Linguistique, littérature, didactique

\title{
Genre and Cognitive Development : Beyond Writing to Learn
}

\section{Charles Bazerman}

\section{(2) OpenEdition}

\section{Journals}

\section{Electronic version}

URL: http://journals.openedition.org/pratiques/1419

DOI: 10.4000/pratiques.1419

ISSN: 2425-2042

\section{Publisher}

Centre de recherche sur les médiations (CREM)

\section{Printed version}

Date of publication: 15 December 2009

Number of pages: 127-138

\section{Electronic reference}

Charles Bazerman, «Genre and Cognitive Development : Beyond Writing to Learn », Pratiques [Online], 143-144 | 2009, Online since 13 June 2014, connection on 30 April 2019. URL : http:// journals.openedition.org/pratiques/1419; DOI : 10.4000/pratiques.1419

(c) Tous droits réservés 


\title{
Genre and Cognitive Development : Beyond Writing to Learn
}

\section{Charles Bazerman}

\author{
University of California, Santa Barbara
}

As writers we all have had the experience of coming to a new perspective, seeing things differently, as the result of having written a paper, a report, an application or other text that has forced us to put together in a new way facts or ideas we have known. We are also aware that at times when we take on the task of writing a specific text our attention is engaged and focused until such time as we consider the problem of writing the paper solved - that is we find our thoughts sufficiently so that writing poses no new significant problems for us. When we emerge from these writing episodes we have solved problems novel for us, had thoughts new to us, and developed perspectives we may not have had before.

In these episodes the basic task we have taken on may have been quite familiar and no new fact may have come to our attention, yet at least the reconfiguration of the familiar helped us put the pieces in a new relation and think new thoughts. The autobiography and personal diary are widely recognized as creating new perspectives on the relations and events in our lives. Even such a mundane task as making a TO DO list can help us look more deeply and coherently at our activities and commitments.

Similarly, when we have gathered new facts or look more closely at texts, writing can help us move to a new stage of thinking. Sometimes, of course, we just learn new details from this exercise without changing our way of viewing things. Yet a fact or detail we gather in the process may help us see things in a different light - this addition changes the landscape in a significant way. Our old way of seeing things does not hold all the pieces together and we have to do some fresh thinking and revisioning in reorganizing the big picture.

At every stage of my writing life, I know I struggled to write some texts - in middle school, in high school, as an undergraduate, as a graduate, and now as a published scholar. If pressed at the time of writing I could explain the coherence of the paper in a micro or mechanical way-for that was the way I was able to keep from drowning in material I was barely able to bring together. But I was not really sure what it all added up to; it wasn't until later - a week later, a month later, years later - that some observation reminded me of the essay, and I had the sense that now I understood what I had written earlier. Not only am I learning as I write, I learn 
from what I have written as the formulations I made rattle around in my mind and change the way I look at things afterward. It is that new way of looking which then reveals to me a deeper sense of what I had in fact been struggling to say. In the doctoral students I have supervised, as well, I have seen how the challenging work of the dissertation has that intellectually transformative effect.

As teachers we regularly work with this phenomenon. We notice when an assignment seems to bring out a higher level of thinking than we expect from a particular student. In fact we may design our writing assignments precisely to put students in a position where they need to combine information and ideas in ways new to them, or which requires them to consider issues from an unfamiliar stance. Although students somehow find ways to fulfill the letter and not the spirit of assignments, if we have guessed right about what the next step students were ready to take, we can create an occasion for intellectual growth for some students who get what the assignment is about.

\section{Writing to Learn}

This phenomenon of cognitive refiguration stands behind much of the intuitive appeal of the Writing to Learn (WTL) movement, an enthusiasm that reaches beyond recognition that writing can serve more modest roles in learning through articulating understanding and rehearsing material to fix it in memory. We can find many allusions to the more dramatic cognitive impact of writing in the foundational literature in writing process (such as Emig, 1971, 1977) and Writing Across the Curriculum (Britton 1970). Yet when Durst and Newell (1989) looked at the prior research literature on WTL, they found attention directed toward more basic memory-focused forms of learning through rehearsal, consolidation and retention of material in note-taking, review questioning and summarizing. This memoryfocused writing to learn was evidenced by improved performance on content examinations. The few studies that examine more ambitious forms of learning (Newell, 1984; Newell \& Winograd, 1989) take a very broad approach contrasting the connective and global planning aspects of essay writing with memory enhancement from note-taking. Bereiter and Scardamelia's (1987) findings about growth in student writing strategies from knowledge telling to knowledge transforming also point in the same direction. Langer and Applebee (1987) move one step further in noting that different kinds of writing activity lead students to focus on different information. The idea that the kind of writing you did mattered was further substantiated by Cooper and MacDonald (1992) who noted that students who kept academic journals framed by academic questions performed better on their essays than students who wrote dialogic response journals or wrote no journals. Ackermann (1993), in reviewing studies until then found that studies in total were inconclusive with no robust learning gains running across all studies, suggested that it was not simply the act of writing that lead to learning. Rather the great variation in the results of the studies, which employed many different writing tasks in many different situations, suggested that learning through writing was a matter of task and genre choice under appropriate conditions. Discipline and genre specific applications have continued to flourish as teachers have found them useful to foster discipline specific learning and thought development (Bazerman et al., 2005). Boscolo and Mason (2001), in a particularly interesting study, provide evidence of how engagement with writing deepens conceptual understanding within subject matter and which transfers to other subject areas. The volume in which this study appears (Tynjala, Mason, \& Lonka, 2001) contains several other studies that provide other evidence of higher cognitive development through writing. 
Klein (1999) examines the WTL literature to sort out suggested mechanisms by which writing might affect learning and examines the published data that might support each. He focuses attention not so much on the character of the produced text as on the practices that are engaged as one produces the text - that is he looks at cognitive mechanisms engaged in the writing process. He clusters the mechanisms suggested in previous literature in four groups:

1. versions of Britton's "shaping at the point of utterance" that find cognitive gain in the act of formulating and transcribing text;

2. forward search hypotheses, placing emphasis on how the externalized text supports review and reformulation;

3. genre related hypotheses, focusing on how genres require the writer to search for and organize knowledge, to link ideas, to structure relationships with audiences, and to create stances toward material;

4. backward search hypotheses, concerning the elaboration and structuring of text to be able to be intelligible by others at a distance (what some in an oversimplification call the decontextualization of text, obscuring the new contexts mediated by texts).

He finds some evidence for each, but generally finds them under-investigated, with genre hypotheses being the most tested and supported to that date. I point out that the genre distinctions in that literature, which I have also reviewed above, are rather general and form based. They are not tied to activities beyond generalized classroom practice-such as journals, study questions, and essays. The effects seem to be associated with the specific nature of tasks, with study questions leading to increased recall and essays associated with connecting ideas (see also Newell, 2006; McCutcheon, 2007). This pattern is reminiscent of Scribner and Cole's (1981) finding that the cognitive effects of literacy were varied and tied to the institutionally embedded practices which literacy was used for. Looking at cognitive practices in different forms of writing means considering writing processes as multiple and varied, depending not just on personal characteristics of the writer but on the genre, situation, and social activity system within which the writing is taking place and which support the writing in various ways. For example, though there may be variation among the writing processes of students writing an impromptu essay in their class, that same group of students will engage a different set of processes when they are at work on the student newspaper, and a different set of processes when they are filling out forms the next morning in the registrar's office. Even within the individual variations of students in each situation, there will be commonalities of most students in the situation that will contrast with the commonalities of the other situations. (Newell (2006) in reviewing the WTL literature follows this path in pointing toward the necessity of studying writing within disciplinary cultures in the K-12 settings, as I had begun examining in higher education settings in 1981).

Klein notes that all four cognitive hypotheses he finds in the writing to learn literature are on a spectrum of problem solving around producing, planning, reflecting on, and structuring text - and thus are not mutually exclusive nor fully independent. I would point out, further, that the specific situations and associated genres would influence planning, structuring, reviewing, and audience accommodation, so that perception of a situation and a genre decision might affect them all. In a related study of students in grades 4, 6 and 8 writing about a science experiment, Klein (2000) found elements of all four kinds of cognitive mechanisms contributing to learning among various students, but he also noted that the mechanisms required various depths of compositional knowledge to be put into effect, with shap- 
ing at the point of utterance requiring the least, and genre and text structuring requiring the most. While much evidence suggests that emergent writers early on exhibit some genre knowledge (Donovan \& Smolkin, 2006; Sandbank, 2001), Klein's finding suggests a possibility that a more explicit knowledge of genre and text structuring may incorporate, reframe, and direct the other kinds of cognitive activity triggered by writing that may affect learning - in an instance of sublation or aufhebung which we will discuss below.

Bangert-Drowns, Hurley, \& Wilkinson (2004) in a metanalysis of 48 WTL studies noted small but significant genre effects on writing to learn, as measured by conventional measures of academic achievement at all levels of education from elementary to higher education, with the exception of grades 6-8 where writing to learn tasks had a cumulative negative effect size. The authors speculate that the negative effect in middle school may have to do with the restructuring of education around separate subjects, and the introduction to differing forms of writing, so that the genre learning interfered with the learning of material through that genre. The authors also noted that frequent (two or three times a week), shorter (under ten minutes) assignments done over a longer period (a term or longer) had more positive effects than longer writing tasks, done less frequently, for a shorter period. While there was no attempt to consider the effect of particular genres, it was noted that prompts which had a metacognitive component, such as reflection on topics one was confused about, were associated with greater effect sizes. This again suggests the possibility that the cognitive task and practices associated with the production of genres may be related to their potential for supporting various forms of learning.

\section{Vygotsky on Learning and Development}

In the remainder of this essay I want to lay out a theoretical view of how genre might interact with both learning and development, using a Vygotskian lens, considering genres as tools of cognition. The connection between Vygotskian sociocognitive theory and genre theory has been implicit in almost all the work from the North American Genre theory perspective, and explicit in my work, although not always centrally foregrounded. Here I will lay out some of the reasoning more explicitly and coherently so as to suggest a renewed sociocognitive research program in writing to learn and as a heuristic for pedagogic practice.

To develop a more refined view of writing to learn and its relation to cognitive development it is first useful to consider more carefully one of the Vygotsky's core distinctions, between learning and development. While this distinction has not yet become part of the writing to learn discussion, one can see its shadow on the distinction between the effects of notetaking or study question writing and the effects of analytic essay writing.

Psychologists, educational researchers, and writing theorists have pursued Vygotsky's association of cognitive development with children learning cultural tools to regulate their activities and thoughts. Within the North American genre group interest in the historical emergence of these tools and their relation to a Hegelian history of consciousness has been combined in activity-based genre studies with Schutz's ideas about typification in the life world, pointing to the differentiation of modern activity systems and the associated cognition. Much of the research in writing in the disciplines and professions follows this perspective. But this literature has not yet made much of a distinction between learning and development, although Vygotsky in Thought and Language explicitly distinguishes be- 
tween learning and development, arguing that learning leads development (Vygotsky, 1987).

Vygotsky's view contrasts with Piaget's, which treats development as a precondition to learning; development happens outside of learning, and makes learning possible as the learner is made ready to engage in new forms of learning. Development is not influenced by learning, but learning is not possible without development. From this perspective you might say writing to learn is precisely just writing to learn: an opportunity to identify, rehearse, organize and reinforce memory of new material. One must have all the developmental preconditions of writing, including physical ability to record letters, cognitive abilities to code and decode, and the characteristics of short and long term memory needed to write, in order to engage in WTL. Already having attained the appropriate intellectual level to carry out the WTL task, one would not particularly develop a new way of thought in the activity. One would only learn the content of the writing one was rehearsing, and connect it to other things of a similar sort one had already learned. At most, if one was at an appropriate developmental level to reflect on what one had written, one could become more aware of the cognitive processes one was engaged in, but this too would be a learning that one was already developmentally prepared to take part in. WTL studies of note taking and study questions would comfortably fit within this view.

Vygotsky's view also stands in contrast to views which treat learning and development as happening simultaneously, with development being just the accumulation of smaller acts of learning. From this perspective WTL would allow for the accumulation of knowledge as well as new skills of thinking introduced in relation to the assignment and practiced in fulfilling the assignment. This view does allow for intellectual growth through explicit teaching and practice, as one learns to carry out new cognitive tasks. This view, accordingly, does allow us to think of genres as sociocultural cognitive tools which can be transmitted to the student. This brings us part of the way to Vygotsky's views, but not entirely. For example, the research on analytic essay writing as a tool of WTL does measure cognitive change that occurs through the organization, synthesis, and stance taking that are part of this school genre, as revealed through standard school measures and text evaluation. Similarly (but in greater ethnographic detail linking situated activity with text production and text produced), research on writing in the disciplines, workplace, and community (such as the work of Swales \& Najjar, 1987; Bazerman \& Paradis, 1991; Medway, 1994, 1996; Dias et al., 1999; Swales, 1998; Smart, 1998; Beaufort, 2000; Bazerman \& Russell, 2002) demonstrates learning of new forms of situated cognition by learning to write in the disciplinary, professional, and community genres.

Vygotsky's view, however, posits that learning prepares the learner for new stages of development, where at some point the learned material becomes more than the sum of its parts, but is rather added up, reorganized, and reintegrated at a different level, so it becomes seen in a different light. This enables reflection on knowledge, perception, and understanding from a new perspective. Learned material and new stages of development can influence and restructure what one has previously learned in different ways and in different domains. A new functional system of knowledge and thought has developed within which parts take on new significance. This concept of reformulated functional systems may be seen as an instance of Hegel's aufhebung or sublation, where concepts are transformed by the appearance of a new conceptual term. Marx extends this to consider how the transformation in material conditions also transforms conceptual meanings, and changes in conceptual 
orientation in turn changes our perception and engagement with the material. For Vygotsky, Luria (1970), and others in this tradition, each new set of cognitive practices is learned through social interaction, moving by internalization from the interpersonal plane to the intrapersonal. These internalized social tools have the potential for refiguring prior engagements with the material and social worlds. The incorporation of the new tools integrate with and reformulate existing practices. That is, the new practice is first learned as a separate task to be mastered as an absorbing activity in itself, but as it becomes less of a focal challenge, it may interact with other tasks and practices. (Leontyev, 1979, reformulated this insight in distinguishing among activity, act, and operation.)

One consequence of this perspective is that development need not be seen only as a phenomenon of childhood, with adults fully developed with only new learning but no development ahead of them. In the Vygotskian view, development is possible whenever one enters new domains that offer pathways for restructuring and reintegration of thought. Even in pursuing a single domain one can develop as one gains access to higher levels of understanding, perception, and decisions. While these adult forms of development may be more scaffolded by the vocational, community, and recreational activities and structures rather than those of schooling, and thus offer a wider range of possibilities and greater engagement with the activities of the world, their mechanisms of cognitive reformulation are no different than that of children moving through the challenges of different levels of schooling and subject learning.

The most prominent example of how learning leads development in Vygotsky's work is his account of early language learning. In the earliest period of language learning, Vygotsky sees little impact of the language on preexisting cognition based on material relations with the world, although language learning does include a heightened and expanded relation to the world and expanded domains of shared attention with one's interlocutors. But this expansion is all interpersonal, part of the social relation of communicating and learning to communicate with the others around one. Gradually, however, the child starts to engage in private speech, echoing to oneself the community attentions and relations embedded in language interaction. This internalization leads the child to self-regulation of attention and action. At this moment individual cognition begins to change, with a new linguistically based, symbolic rationality developing in the child. Whereas previously the child's cognition was directly related to the material experience and relations to the world and others, now that relation begins to be mediated by the child's internalized symbolic repertoire - a repertoire that not only names the world, but regulates behavior and gives directions, takes stances, and makes plans. At this point language moves from simply a newly acquired but separate functional system - a means of communicating and interacting with others - into reconfiguring previously acquired functional systems. It remakes the old as something new, and one finds it increasingly hard to recover what it felt and thought like to live in a pre-linguistic world. This is a qualitative change in the nature of thought and perception, which we might call a developmental leap.

\section{Developing a disciplined view of language}

While the internalization of speech and its functional reorganization of consciousness around age three is perhaps the most dramatic and foundational of the transformations, turning us into deeply symbolic and linguistic creatures, these transformations may continue to occur in smaller, more local ways that are nonethe- 
less consequential throughout our life. One such example occurs in every one of us that has become a professional language instructor or researcher at the point at which we learn the formulations of prescriptive grammar, language structure, rhetorical analysis, genre analysis, or whatever techne of language that brought us from a direct expressive sense of language to a technical one. At first we learn these technes in our schooling somewhat cumbersomely in interaction, with scaffolded definition, identification, application, and practical use. These themselves are embedded within particular genres of rules, explanations, textbooks, and school exercises. In pursuing these tasks and accomplishing the genres associated with assignments, students must engage in all four sorts of the cognitive mechanisms that Klein saw hypothesized in the literature: putting together of sentences about the material and ideas (shaping at the point of utterance); forward searching (examining what you have already accomplished to see how to extend it forward); genre based searching for relevant knowledge and bringing the knowledge together in patterned discourse; and backward searching to elaborate and organize the text to be comprehensible for others. At first these are carried out in a fairly contained learning practice, tied to an instructional situation.

At some point we can carry this mode of thought on our own outside of the support of classrooms and tutors, and we are able to struggle through homework, or we even remember the rules and concepts totally outside of school-centered activities. At some point these technical tools of language then start interacting with our own writing and even speaking practices, perhaps starting to flower in our secondary or tertiary education. We use these technes to solve our personal linguistic problems, and if we are ever stuck in mid-sentence we can remember the trace of a rule or bit of advice to carry us on. At some point we spontaneously note these technical matters everywhere as we come to see all the words of others not just as a bunch of directly communicated meanings, but a complex linguistic environment. Our perception of language has been transformed into a new functional system and we come to process our hearing and reading in a different way. While there may be moments that hail us back to our earlier more naïve stance towards language, for the most part we find it hard to remember what language felt like before we incorporated our technical sense of it. We notice and are frustrated when our students don't have that same relation to language that we do, not seeing it the way we want them to see it, not identifying language practices how we would like them to, not able to make language choices on the basis of the principles that now seem natural to us.

We have good evidence that direct instruction in prescriptive grammar and doing drill exercises or related practices such as labeling parts of speech and diagramming sentences does not translate into direct improvements in grammatical correctness in produced sentences in the short term - that is in close enough proximity to be measured without so much intervening complexity that we can make no association (Hillocks, 1986). Accordingly many, including myself, have diminished the role of direct grammatical instruction within writing pedagogy, and have come to rely on students' ability to create meaningful utterances and gradually expand them through modeling. Insofar as we teach grammar and syntax it tends to be in situ, in revision, in correction comments, or in individualized conference-that is at the point of practical need. Yet we still cannot fully wean ourselves and others from the belief that explicit knowledge of grammar and syntax is an important part of the writer's craft, as well as the editor's. As experienced writers we regularly use prescriptive grammatical knowledge to correct, revise and even produce sentences. We use morphological and syntactic abstractions to diag- 
nose difficult sentences as well as to consider phrasing alternatives. We use prescriptive syntax to orient ourselves when we get lost in a tumble of phrases. As we become language experts, it even becomes part of our fundamental understanding of the system of language (although the grammars change and become intellectually more sophisticated). What is at first learned as a concrete set of literate practices is at first used only in the concrete practice of exercises. But at a certain point, for some, it integrates with our perception of sentences, our activities of revision, and construction of sentences. At this point it reshapes our perceptions of language and processes of making meaning. Yet, if we have not reached that point of sublation, the grammatical knowledge has little to do with composing. I frequently have had the experience of working in individual conference with fairly fluent writers, and when I ask them to think about a technical problem in the construction of the sentence or consider an alternative syntax, they respond only at the level of meaning: they say, "What I am trying to say is..." and then repeat the existing sentence. The meaning is tied to the phrasing, which cannot yet be seen as a technical construct to be manipulated for different meaning potentials, despite students' ability to complete grammar exercises correctly as a discrete practice.

Thus writing at the sentence and subsentence level goes through many transformations as we integrate new forms and levels of understanding of the texts we and others produce. What those transition moments are, what threshold of knowledge and internalization is necessary, what triggers the change-I leave as open questions. The point here is that learning concrete literate practices within the context of the genres of grammatical instruction-including rules, exercises, and diagrams - at first seems to have no transfer value into functional use in writing and revision. Later, however, these integrate with the meaning making aspects of writing to create a new functional system of writing. We may also say something similar happens with reflective understanding of other levels of composing, such as text structuring devices, genre expectations, audience and situation concerns, and activity consequences within larger social systems.

\section{Development of Disciplinary Cognition}

There are close parallels in this relation between technical vocabularies and deeper understanding in every field that names and taxonomizes fundamental parts. Learning the names of trees and their distinctive features only becomes part of creative thinking about botany and evolution after the scheme has become internalized, to reshape perception, which allows for fresh observation and fresh thought. Learning taxonomies through repeating, applying, or identifying taxonomic items, can be a kind of rote writing to learn. Yet the internal logics within the taxonomies and distinctions to be comprehended once it has internalized the parts provides the basis for a new disciplined way of seeing and thinking once one has internalized the system - so that one sees and thinks within the systematic relations of the system. Names of felines invoke not only the names of other felines, but distinctions from canines in characteristics and ways of life. They also invoke understandings of mammalian forms of life, relations to all other fauna and flora, as well as creating the potential for integrating concepts of ecology at some later date. We come to know these relations not just by the lexicon, but by the kinds of discourses within which these taxonomized terms and the objects they represent are discussed.

Beyond learning to read and reproduce the taxonomies, there are in most fields genres of identification, application, inquiry, analysis, synthesis, planning, and 
coordination using those terms and concepts embedded in the namings of the field. There are also genres that repeat, interpret, synthesize and deploy the collective literature of the field to communicate knowledge, address specific tasks, identify new findings, deal with conceptual struggles, and lay out collective research and action agendas. These genres do not begin to exhaust the kinds of tasks carried out by texts in the field, texts that at first are carried out with great struggle, but then become ways of expression, thinking, seeing, and ultimately remaking one's prior knowledge of the field and prior knowledge of the world. In this way one learns to think and act as a member of one's profession or discipline-internalizing a view of the world that pervades not only what one has learned and done in the field, but how one relates to others and the world.

Each field is different in its cognitive consequences, as you know when you have an informal conversation with a sociologist, or a lawyer, or a medical doctor. Each profession shapes a distinct view of the world that lends unique perspectives to the conversation. Each distinct professional perspective may not be fully transparent to other participants from other professions. As I started to hang out with sociologists for a while, at some point I began to see things more sociologically in a way that went beyond the formulas I learned in the first-year introductory course. And in talking to students I can start to notice who has some of that sociological vision and who does not, just as I can notice who has developed some sophistication about language. In doing work in language across the curriculum and in the disciplines, I have found some accomplished colleagues who have become very thoughtful about writing in their field, have read a lot in language as well as the sociology and history of science - they are articulate about their writing and how they mentor their students in writing, and approach those tasks in a selfconscious professional way. On the other hand I have found smart, accomplished colleagues in other disciplines who have little vocabulary for discussing writing beyond the corrective grammar they learned in high school. Although they have learned the genres of their profession and are successful in them, their reflective ability to manipulate them is limited because of a lack of linguistic and rhetorical vocabulary and analytical methods. Their fairly developed language practice has not been professionalized or transformed through internalizing those disciplinary knowledges which would provide them a more sophisticated stance. This patterned variation in cognition around the literate practices of disciplines and professions suggests how pervasive the effects of writing have been. The emergence of differentiated written genres within differentiated activity systems have shaped the practices of knowledge, thought, and reasoning in the world since the introduction of literacy five thousand years ago (Bazerman, 2006; Bazerman \& Rogers, 2008a, 2008b).

Each domain of learning provides opportunities to learn in the genres of the classroom and profession through which we rehearse the typical objects, relations, and reasoning of the field. We then learn not just to talk but to learn the forms of attention and reasoning which the language points us toward. The words of the field become associated with practices and perceptions, changing our systems of operating within the world and writing others. These ways of being and seeing may then interact with other functional systems within us, transforming them as well. We may view the process of being socialized into a literate domain not just as a set of social learnings, but as a cognitive apprenticeship (Brown, Collins, \& Duguid, 1989) with punctuated periods of marked development where the learnings become integrated with other existing or parallel developed functional systems to create new functional systems. The learnings are organized into the genres of 
presentation and practice, each requiring a particular repertoire of cognitive practices and work for their reception and production. The line of reasoning presented here perhaps can provide a means of specifying the various ideas that have aggregated around schema theory.

In this punctuated process previous learning that developed around the spontaneous concepts of everyday life (as Vygotsky described them) becomes reorganized and reintegrated within "scientific concepts", as Vygotsky called them, that are introduced and practiced through the genres of schooling, disciplines, and professions. This development of new ways of thinking, of approaching experience, of adopting new stances and engaging new experiences occurs within culturally and institutionally shaped Zones of Proximal Development (ZPD) (not Zones of Proximal Learning) that Vygotsky identified (Vygotsky, 1978). These ZPDs occur in the collaborative participation of typified activities and discursive forms familiar to the instructor, adult or more skilled peer, but at which the learner is not yet adept. No doubt that interaction with peers or others may lead to spontaneous learning and formulation, but it appears that LSV had in mind these more structured interactions built around discursive activities familiar to one of the participants. In this ZPD the learner becomes familiar with the orientations, language, and practices in the domain, which at some point become familiar enough and internalized enough that they can be integrated into perception, thought, and activity, as well as the reformulation of capacities already developed. This developmental process is deeply tied to creating reflective structures of understanding, perception, and action, and thus self-regulation.

This Hegelian understanding of development, with a new synthesis reformulating earlier material within a new functional system, helps us understand the familiar experience of writers, that writing helps them reorganize their thoughts and reintegrate their knowledge into a more comprehensive picture. Further, if we see these integration tasks as accomplished within the genres and activity systems of school, disciplinary, and professional work, we have the mechanism by which students develop into disciplined and disciplinary thinkers, learning how to locate and inscribe subject-relevant facts and data in ways appropriate to the schooled versions of the field and fitting the chronotope of the genres they are writing in (Bakhtin, 1982). Students learn how to produce the kinds of thoughts appropriate to the assigned genres, using the concepts and discursive tools expected in the genres, and they learn how to locate their findings, analysis, and thought within the communal project of academic learnings. Further, we find in integrative genres a mechanism by which fully socialized professionals develop the leading edge of the field, moving the field onto the next level of work, influencing both group cognition and the cognition of participating individuals. There is an interaction between learning to write in more advanced, new, or hybrid forms and cognitive growth for both individual and community or "thought collective" (Fleck, 1979).

In all these instances, whatever the level of cognitive activity required, genres identify a problem space for the developing writer to work in as well as provide the form of the solution the writer seeks and particular tools useful in the solution. Taking up the challenge of a genre casts you into the problem space and the typified structures and practices of the genre provide the means of solution. The greater the challenge of the solution, the greater the possibilities of cognitive growth occurring in the wake of the process of solution. Thus in school and in the professions the interaction between group and individual cognitive development can be seen as mediated by activity system-specific genres. 


\section{References}

ACKeRmANN, J. M. (1993). "The promise of writing to learn". Written Communication, 10: 334-370.

BANGerT-Drowns, R.L.; Hurley, M. M.; Wilkinson, B. (2004). "The effects of school-based writing-to-learn interventions on academic achievement: A metaanalysis". Review of Educational Research, 74: 29-58.

BAKHTIN, M. (1982). "Forms of time and of the chronotope in the novel". In The Dialogic Imagination: Four Essays. Austin: University of Texas Press.

BAZERMAN, C. (1981). "What written knowledge does: Three examples of academic discourse". Philosophy of the Social Sciences 11:3: 361-88.

- (2006). "The Writing of social organization and the literate situating of cognition: Extending Goody's social implications of writing”. In: Olson, D.; Cole, M (Eds.). Technology, literacy and the evolution of society: Implications of the work of Jack Goody. Mahwah, NJ: Erlbaum.

Bazerman, C., Little, J., Chavkin, T., Fouquette, D, Bethel, L. Garufis, J. (2005). Writing across the curriculum. Reference Guides to Rhetoric and Composition, Parlor Press and WAC Clearinghouse. Available in http://wac.colostate.edu/books/bazerman_wac/

Bazerman, C., PARAdis, J. (Eds). (1991). Textual dynamics of the professions. Madison WI: University of Wisconsin Press.

BAZERMAn, C., Rogers, P. (2008 a\&b). "Writing and Secular Knowledge". In: Bazerman, C. (Ed). Handbook of research on writing. Mahwah, NJ: Erlbaum.

BAZERMAN, C., RUSSELL, D. (Eds.). (2002).Writing selves/Writing society. Fort Collins, Colorado: WAC Clearinghouse. Available at: http://wac.colostate.edu/books/selves_society/

BeAufort, A. (2000). "Learning the Trade". Written Communication 17:2 : 185-223.

Bereiter, C.; SCARdamalia, M. (1987).The psychology of written composition. Hillsdale, NJ: Erlbaum.

Boscolo, P., MASON, L. (2001) “Writing to learn, Writing to transfer”. In: Tynjala, P.; Mason, L.; Lonka, K (Eds.). Writing as a learning tool: Integrating theory and practice. Dordrecht, Boston \& London: Kluwer Academic,.

Britton, J. (1970). Language and learning. London: Penguin,

Britton, J; Burgess, T.; MARTin, N; MCLeod, A.; Rosen, H. (1975). School councils research studies: The development of writing abilities. London: McMillan.

Brown, J. S.; Collins, A.; Duguid, P. (1989). "Situated cognition and the culture of learning". Educational Researcher, 18: 32-42.

Dias, P; Freedman, A; Medway, P. Paré, P. A. (1999). Worlds apart: Acting and writing in academic and workplace settings. Mahwah, NJ: Lawrence Erlbaum.

Donovan, C.: SMOLKin, L. (2006). "Children's understanding of genre and writing development”. In: MacArthur, C. A.; Graham, S.; Fitzgerald, J. (Eds.). Handbook of writing research. New York: Guilford Press.

DuRST, R. K.; NEWELL, G. E. (1989). “The uses of function: James Britton's category system and research on writing". Review of Educational Research 59:4:375-394.

EMIG, J. (1977). "Writing as a mode of learning". College Composition and Communication 28 122-128.

FLECK, L. (1979). The genesis and development of a scientific fact. Chicago: University of Chicago Press,

HILlOCKS, G. (1986). Research on written composition. Urbana, IL: NCTE.

KLEIN, P.D. (1999). "Reopening inquiry into cognitive processes in writing-to-learn". Educational Psychology Review 11:3: 203-270. 
- (2000). "Elementary students' strategies for writing-to-learn in science". Cognition and Instruction 18:3: 317-348.

LANGER, J., APPlEBEE, A. (1987). How writing shapes thinking: A study of teaching and learning. Urbana, IL: National Council of Teachers of English.

LEONTYEV, A.N. (1979). "The problem of activity in psychology". In: Wertsch, J.V. (Ed.). The concept of activity in Soviet psychology. Armonk, NY: Sharpe.

LURIA, A.R. (1970). "The functional organization of the brain". Scientific American, 222(3): 66-78.

MacDonald, S. P.; CoOPER, C. (1992). "Contiutions of academic and dialogic journals to writing about literature". In: Herrington, A.; Moran, C. (Eds.). Writing teaching and learning in the disciplines. New York: MLA.

MCCUTCHEON, D. (2008). "Writing and cognition: Implications of the cognitive architecture for learning to write and writing to learn". In: Bazerman, C. (Ed.). Handbook of research on writing. Mahwah, NJ: Erlbaum.

MedwAY, P. (1994). "The language component in technological capability". Lessons from architecture. Journal : 85-107.

- (1996). "Virtual and Material Buildings: Construction and Constructivism in Architecture and Writing". Written Communication 13: 4: 473-514.

NEWELL, G. E. (1984). "Learning from writing in two content areas: A case study/protocol analysis". Research in the Teaching of English 18, 265-287.

- (2006). "Writing to learn: How alternative theories of school writing account for student performance". In: MacArthur, C. A.; Graham, S.; Fitzgerald, J. (Eds.). Handbook of writing research. New York: Guilford Press.

NEWELL, G. E. \& WinOGRAD, P. (1989). "Writing about and learning from history texts: The effects of task and academic ability". Research in the Teaching of English 29: 133-163.

SANDBANK, A. (2001). "On the interplay of genre and writing". In: Tolchinsky, L. (Ed.). Developmental aspects in learning to write. Dordrecht: Kluwer Academic.

SCHUTZ, A. (1967). The problem of social reality. The Hague: Martinus Nijhoff.

SCRIBNER, S.; Cole, M. (1981). The psychology of literacy. Cambridge, MA: Harvard University Press,.

SMART, G. (1998). "Mapping conceptual worlds: Using interpretive ethnography to explore knowledge-making in a professional community". Journal of Business Communication, 35: 1: 111-127.

SWALES, J. (1998). Other Floors, Other Voices: a textography of a small university building. Mahwah, NJ: Erlbaum.

SWALES, J. \& NAJJAR, H. (1987). "The writing of research article introductions". Written Communication 4: 2, 175-191.

TyNJALA, P.: MASON, L.: LONKA, K (Eds.). (2001). Writing as a learning tool: Integrating theory and practice. Dordrecht: Kluwer Academic.

Vygotsky, L. (1986). Thought and language. Cambridge, MA: MIT Press. - (1978). Mind in society: The development of higher psychological processes. Cambridge, MA: Harvard University Press. 